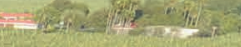

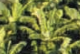

4.

1)

H.1
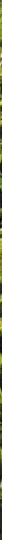

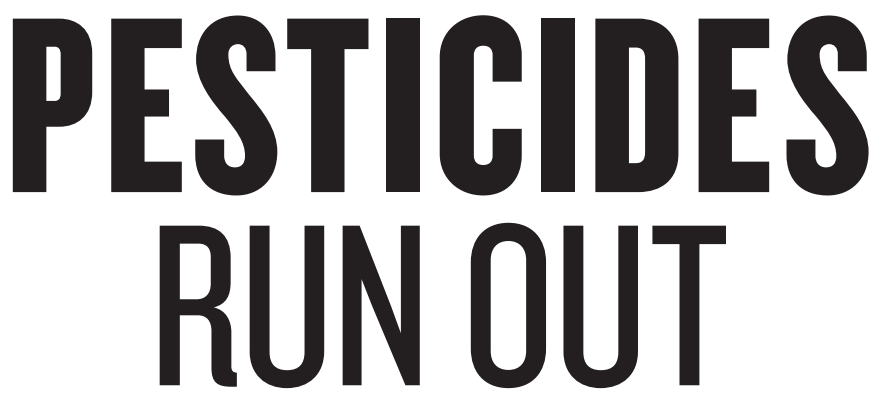

Resistance is exhausting the agricultural arsenal against insects, weeds and disease. New biological approaches could help.

BY BROOKE BOREL

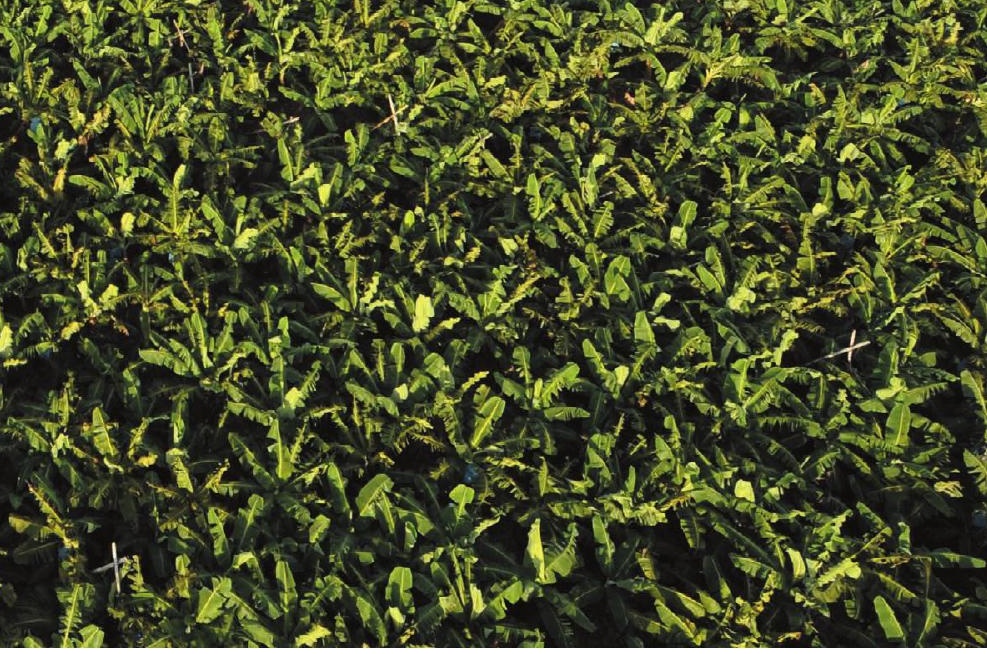

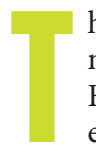

he first thing Broc Zoller does every morning is check the weather forecast. For the past five years, California farmers like him have struggled through historic drought. Now they face the opposite

A crop duster sprays fungicide on a banana plantation in the Philippines.

problem. In the first months of 2017, it has already rained more than it did all of last year in Kelseyville, where Zoller grows wine grapes and walnuts, and leases out land to pear growers. The muddy conditions have slowed pruning efforts and delayed the application of sprays used to control key insect species over the winter. If the rains continue as spring arrives, the combination of warmth and wetness could spark fungal and bacterial infections. To protect his crops, Zoller suspects he will have to use several conventional pesticides.

But the selection is getting slimmer, thanks to resistance. Fire blight, a bacterial disease that can cause weeping cankers on pear-tree trunks, generally responds to antibiotics, but the drugs can stop working if overused. And pear scab - a fungus that leaves unsightly brown lesions on the fruit - calls for multiple fungicides throughout the growing season. Zoller, who also works as an agricultural pest-control adviser, uses some of these chemicals just once before they start to lose effectiveness. "The resistance comes so quickly," he says. "You hope there aren't too many rains so that what you have in your arsenal can get you through."

Resistance to conventional pesticides - among insects, weeds or microbial pathogens - is common on farms worldwide. CropLife International, an industry association based in Brussels, supports efforts that have counted 586 arthropod species, 235 fungi and 252 weeds with resistance to at least one synthetic pesticide (see 'The rise 
of resistance'). And that's just the cases that scientists have formally identified and recorded.

For several decades, the agrochemical industry has simply rolled out new chemicals to replace the old ones. But for many crops, the pipeline is drying up. The rate of discovery of pesticides has "gone almost to zero in the last ten years or so", says Sara Olson, a senior research analyst at Lux Research in Boston, Massachusetts, which specializes in emerging technologies. New chemicals are difficult and expensive to find and develop. And once one is in use, pests will soon develop resistance to it, unless its application is carefully managed.

So scientists are pursuing alternatives that may reduce or replace synthetic pesticides. They are particularly interested in biological solutions, including microbes, genetic engineering and biomolecules. Even major chemical companies see enough promise to invest in the work. That doesn't spell the end of synthetic pesticides, but it could help to slow the spread of resistance. Some approaches might also help farmers to reduce costs, protect workers and please a public that is increasingly wary of synthetic chemicals.

"Emerging pest resistance is a big driver for finding alternatives," says Olson. "But for the most part, it's not a choice between chemicals and biological or other options - it's the recognition that you can do more in a more nuanced way with some of these tools."

\section{MICROBIAL HELPERS}

At the start of the twentieth century, a mysterious epidemic was wiping out prized silkworms across Japan. In 1901, the bacteriologist Ishiwata Shigetane uncovered the cause - an unknown soil bacterium that he found inside a dead silkworm. A decade later, in the German province of Thuringia, biologist Ernst Berliner found the bacterium in flour-moth caterpillars - a common pest — and formally described the insect killer, which he named Bacillus thuringiensis $(B t)$.

Proteins produced by $B t$ perforate the intestines of several insect species, and have been used as a natural pesticide for decades. Scientists have long been looking for more pest-killing microbes. "It was not a young field when I was a graduate student, nearly 45 years ago," says Roger Beachy, a plant biologist and pathologist at Washington University in St. Louis, Missouri.

But microbes are now making their way to the agrochemical mainstream. In 2012, Bayer CropScience paid a reported US\$425 million for AgraQuest, a biopesticide company based in Davis, California. Over the past few years, other multinational companies, including DuPont, Monsanto and Syngenta, have also invested.

Beachy, who was a pioneer in developing genetically modified (GM) food crops, has plunged into microbes along with Indigo Agriculture, a start-up based near Boston. Indigo scientists select microbes to enhance crops' endobiomes - the microorganisms that live within the tissues of the plants - and incorporate them into a coating that can be applied to seeds. When the seedling sprouts, its stem gets small scrapes as it pushes through the tough seed. These scrapes should allow the microbes to colonize the plant and help protect it against environmental stress, such as drought. Last year, the company raised a reported $\$ 100$ million in funding.

Indigo is tight-lipped about the specific strains it uses. But already, farmers have planted the company's coated seeds on 20,000 hectares of cotton and 8,000 hectares of wheat in the United States. That's not a lot compared with the 4 million hectares of cotton and 21 million hectares of wheat that US farmers planted in 2016, but it suggests that people are willing to try it out. Beachy, who initially served as the company's chief scientific officer and still chairs its science-advisory board, says that Indigo is actively looking to add pest resistance to the advantages its coating confers. "I would hope that within five years there will be a handful of products available," he says.

Other companies are already using microbes as pesticides. Marrone Bio Innovations in Davis grows microbes and uses them and the chemicals they produce to kill pests. The company has screened 18,000 microbe genomes and has, so far, brought 5 products to market. One of its microbes - a strain of the bacterium

\section{THE RISE OF RESISTANCE}

The number of pests (including insect and plant species) resistant to at least one form of synthetic pesticide has been steadily on the rise for decades, as has the cost of developing such chemicals.
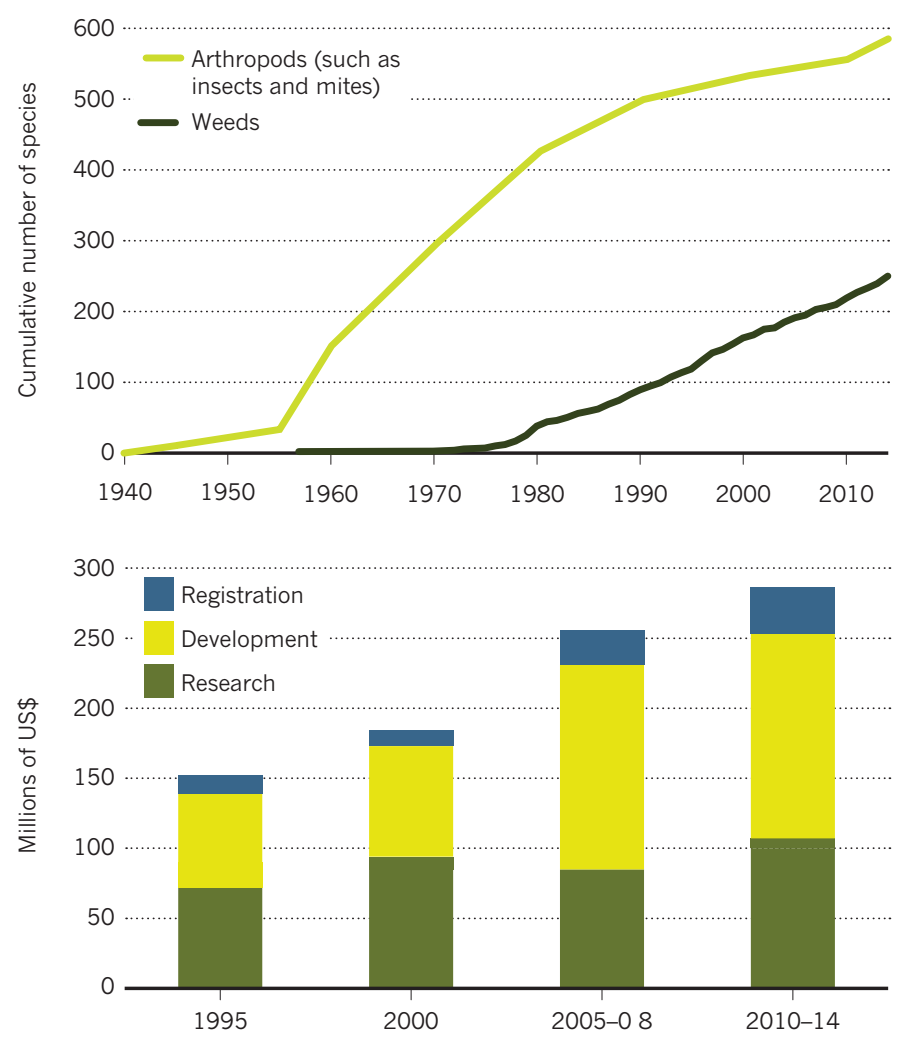

Burkholderia - produces multiple types of chemical, depending on how it's grown. It is used to produce an insecticide and a nematicide (used to control certain worms), and it may also be able to produce a herbicide.

Burkholderia "has the genetic machinery to make multiple classes of compounds", says Pamela Marrone, the company's chief executive and founder, possibly because of how it evolved to defend itself.

Historically, farmers have been wary of biopesticides, in part because the materials are trickier to use than synthetics. Some can degrade quickly in sunlight or heat, for example. And they aren't generally as effective as synthetics - they simply don't pack the same lethal punch. But a direct replacement isn't necessarily the point. Instead, biopesticides can reduce synthetic-chemical use, says Marrone. The microbes "don't have to work perfectly as well as the chemicals, although some of ours do stack up", she adds. "But when they're integrated in, they get better yield and quality than chemicals alone."

\section{CRISPR'D RESISTANCE}

The powerful gene-editing tool CRISPR-Cas9 has granted scientists new abilities. Although previous technologies - such those that create GM organisms by adding new genes - can directly kill insect pests or make crops impervious to powerful herbicides, engineering crops to resist disease has been trickier.

One reason is how disease-resistance genes are regulated in plant cells. "In nature, resistance genes are typically held on a pretty tight leash," says Adam Bogdanove, a plant pathologist at Cornell University in Ithaca, New York. If they become too active, they can damage the plant. But in conventional GM organisms, scientists can't control where an added gene ends up in the target genome - and disease-resistance genes may not express correctly if they land in the wrong spot. CRISPR is particularly useful, says Bogdanove, because it "lets you control the position of insertion, and therefore control the expression".

Bogdanove is using the technique to make rice that is inherently 
resistant to bacterial leaf streak and blight, two of its most devastating diseases. His collaborator Jan Leach, a plant pathologist at Colorado State University in Fort Collins, is also experimenting with CRISPR and older gene-editing tools to target plant immune systems, breeding rice that is resistant to a wide range of diseases, rather than just one.

Scientists are CRISPRing other crops - particularly plants that weren't widely targeted in the earlier GM revolution, because they were too difficult to engineer. Researchers at Rutgers University in New Brunswick, New Jersey, are using the technique to make wine grapes that thwart downy mildew. A team in the United States has made tomatoes that are resistant to several Pseudomonas and Xanthomonas bacteria ${ }^{1}$. And scientists in Beijing have made powderymildew-resistant wheat ${ }^{2}$.

Altering wheat is challenging because the plant contains three nearly identical genomes. The Beijing team essentially had to target three versions of a resistance gene. With CRISPR, "you are able to knock out several genes simultaneously", says team member Caixia Gao, a plant biologist at the Chinese Academy of Sciences' Institute of Genetics and Developmental Biology.

Industry scientists are smitten, too. Last September, for example, Monsanto signed a non-exclusive licence with the Broad Institute in Cambridge, Massachusetts, which in February won a patent dispute over CRISPR technology. Tom Adams, Monsanto's vice-president of biotechnology, says the company is exploring how CRISPR might be used to enhance disease resistance, drought tolerance and yield in some crops.

But the approach could also be used in ways that increase pesticide use. Adams says that gene editing could create crops that can withstand herbicides, much like Monsanto's existing GM crops that tolerate the chemical glyphosate. But these products are controversial; allowing farmers to use glyphosate liberally has led to over-reliance on it.

\section{RUNNING INTERFERENCE}

Long before CRISPR promised to change the world, bioscientists were excited about another genetic way to control pests: RNA interference (RNAi), a mechanism in which double-stranded RNA molecules are taken up by an organism and effectively shut down a particular gene.

In some ways, the technology could make it easy to target specific pests. It is possible to start with a precise genetic sequence and then build small molecules to interfere with gene activity, says Sonny Ramaswamy, director of the National Institute of Food and Agriculture, the researchfunding arm of the US Department of Agriculture, which is supporting several RNAi studies.

The trick is slipping the molecule inside its target at the right place and time. For example, the RNA needs to be present on or throughout an entire plant to defend against sucking insects. That can be ensured through genetic engineering, but the process is expensive and faces the same regulatory and public hurdles as creating any GM organism. And if the pests were to become resistant to the RNAi, researchers would have to engineer an entirely new plant to replace it.

Both academic and industry scientists think a better option may be to apply the RNAs directly to crop leaves or roots. That is more "convenient and flexible than transgenic crops", says Xuexia Miao, a plant-insect interaction researcher at the Institute of Plant Physiology and Ecology at the Shanghai Institutes for Biological Sciences in China.

In 2015, she and her team showed ${ }^{3}$ that RNAi delivered through the roots of rice and maize helps to protect against insects. But an irrigation system may be difficult in practice: soil teems with microbes and enzymes that can chop up the RNA before it reaches the plant. Miao is also working on sprays that could deliver RNAi directly to plants and insects.

Companies including Monsanto and Syngenta are interested in RNAi, too. Monsanto says its first products - one to protect against the mite Varroa destructor, a pest of honey bees, and another against flea beetles that attack oilseed rape (canola) - will be on the market by the mid2020s. Syngenta will have its first product, for the Colorado potato beetle (Leptinotarsa decemlineata), "by the early 2020s", says Steven Wall, who oversees regulatory and product-safety strategy for RNAi products at Syngenta in Research Triangle Park, North Carolina.

RNAi technology faces other challenges, too. It seems to be effective against some types of insect, such as beetles, but it is harder to use against moths and their larvae, although the reasons for that aren't clear. The pests that do respond to RNAi could also evolve resistance. "Nature always seems to find a way," says Wall. An RNAi spray "has to be managed like any other product - it shouldn't be used exclusively".

And some scientists argue that, although RNAi may target pests more directly than a broad-spectrum pesticide, there's still a chance of collateral damage. The RNAi could kill beneficial insects that share genes with a pest. In a 2013 review $^{4}$ of the technology's risks, US Department of Agriculture scientists wrote that although RNAi is promising for crop protection, its benefits should be weighed against "the relative environmental risks that the technology poses".

\section{BACK TO THE LAND}

In the meantime, as the pesticide pipeline continues to shrink and resistance grows, farmers need new options. The situation varies from crop to crop and farm to farm, but some fields are down to just one working pesticide. "You are literally developing resistance to the one you have left," says Zoller. "And so you're putting it on a couple times more than you used to, just because it doesn't last as long. And you have nothing else to use."

Zoller is already testing biopesticides, although the products can be inconsistent. "We have them in our research tests every year, because we are hopeful," he says. "Some look pretty good one year, but not the next year, although they're good to integrate in" with conventional pesticides.

As for genetic approaches, Zoller thinks that buyers will be wary, thanks to a pervasive fear of GM foods. Other growers are more optimistic. "CRISPR: I think this is the wave of the future if we're going to survive as an industry," says Tony DiMare, vice-president of the DiMare Company, a US tomato grower. The tech will be particularly important, he says, for environmental stress, pests and disease.

Technology alone won't save the farm. Growers will still rely on oldfashioned practices and land management. Crop rotation, for example, helps to break up the life cycles of pests and pathogens - if farmers don't rotate, planting the same crop year round, they provide ample food for certain pests to thrive. Spacing crops close together can help protect weeds from sunlight. And for other crops, pruning lets in air and light, which can help dry up the dampness that lets moulds thrive.

On California's pear orchards such as the ones Zoller leases, farmers let native plants, including wild oats, rye grass and morning glory, grow between the tree rows. This provides habitat for natural predators that curb insect pests. Zoller says it's necessary to use all approaches - new technology and older methods - to protect food and profits.

For any crop, pest management is an ongoing thing, he says. New technologies will also be something farmers look at. "It helps to have a lot of tools." "

Brooke Borel is a science journalist in Brooklyn, New York. This work was partially supported by a 2016 fellowship at the Alicia Patterson Foundation.

1. de Toledo Thomazella, D. P., Brail, Q., Dahlbeck, D. \& Staskawicz, B. J. Preprint at BioRxiv http://dx.doi.org/10.1101/064824 (2016).

2. Wang, Y. et al. Nature Biotechnol. 32, 947-951 (2014).

3. Li, H., Guan, R., Guo, H. \& Miao, X. Plant Cell Environ. 38, 2277-2285 (2015).

4. Lundgren, J. G. \& Duan, J. J. BioScience 63, 657-665 (2013). 